\title{
CARACTERIZACIÓN FUNCIONAL Y ESTRUCTURAL DE GENES ASOCIADOS A PREECLAMPSIA EXPRESADOS EN LA PLACENTA HUMANA
}

\author{
Titulo corto: Genes Asociados a Preeclampsia \\ VERÓNIKA CEBALLOS-NÚÑEZ, ALEJANDRA RODRÍGUEZ, \\ JOSÉ MARÍA SATIZÁBAL, JULIO CÉSAR MONTOYA, ADALBERTO SÁNCHEZ. \\ FELIPE GARCÍA-VALLEJO* \\ Grupo de Investigación del Laboratorio de Biología Molecular y Patogénesis. \\ Departamento de Ciencias Fisiológicas. Escuela de Ciencias Básicas. \\ Facultad de Salud. Universidad del Valle. Cali. Colombia. \\ Sede San Fernando, Edificio 120 oficina 508. Calle 436-00. Cali. Colombia. \\ * Correspondencia: Dr. Felipe García-Vallejo PhD. Director Científico Email: labiomol@gmail.com
}

Recibido: Agosto 3 de 2015

Aceptado: Diciembre 17 de 2015

\begin{abstract}
Resumen
Introducción: La preeclampsia continúa siendo la primera causa de morbimortalidad perinatal. El conocimiento sobre su etiología molecular se ha incrementado en los últimos años debido al avance en la aplicación de las ciencias "ómicas". Ello ha llevado a identificar genes candidatos que participarían en su patogénesis.
\end{abstract}

Objetivo: Identificar y caracterizar estructural y funcionalmente genes expresados en placenta que se asocian con preeclampsia.

Métodos: A partir de una revisión de literatura de los últimos diez años, se identificaron 16 genes cuya expresión en placenta estaba asociada con la patología. Se realizó la minería de datos incluyendo las siguientes variables: número de genes, tamaño de los genes, número de exones codificantes, islas $\mathrm{CpG}$ y las familias de los diferentes elementos repetidos en una ventana de $100 \mathrm{Kbp}$. Mediante un análisis bioinformático, usando los diferentes recursos del NCBI (www.ncbi.nlm.nih.gov) y del Genome Browser de UCSC (http://genome.ucsc.edu/).

Adicionalmente se usó el portal BioGPS (http://biogps.gnf.org/\#goto=welcome) se determinaron los niveles de expresión de cada gen por tejidos.

Resultados: Se registraron diferencias en la cromatina que contiene las familias de elementos no codificantes de los genes asociados en comparación con los controles (Prueba de Kruskall-Wallis, $\mathrm{P}=0.0341824)$. Los genes LEP, EBI3, PROCR, FSTL3, HEXB, INHBA y ENG fueron los que registraron el mayor puntaje z en placentas preeclámpsicas.

Conclusión: La aplicación de las herramientas bioinformáticas se convierte en un instrumento potente para el análisis integrado de la expresión de genes y su papel en la patogénesis de la PE. Esto conllevaría a la identificación temprana de mujeres afectadas.

Palabras claves: Preeclampsia, Expresión génica, Perfiles de expresión, Meta-análisis, Minería de datos, Bioinformática, Cromatina. 


\title{
STRUCTURAL AND FUNCTIONAL CHARACTERIZATION OF GENES ASSOCIATED WITH PREECLAMPSIA EXPRESSED IN HUMAN PLACENTA
}

\author{
Short title: Genes Associated with Preeclampsia
}

\begin{abstract}
Introduction: Preeclampsia still is the main cause of perinatal morbi-mortality; due to the advance in the application of the omics sciences the knowledge about its molecular etiology has increased in the last years, this has led to the identification of candidate genes, which would be involved in its pathogenesis.
\end{abstract}

Objective: To identify those genes, expressed in placenta that are associated with preeclampsia and compare their structural and functional characteristics.

Methods: From a literature review, 16 genes were found, whose expression in placenta was associated to the pathology. Data mining was performed including the following genomic variables: number of genes, genomic size, coding exon count, $\mathrm{CpG}$ islands and repeat elements in a 100Kbp window. For the Bioinformatics analysis, we used different resources of the NCBI (www.ncbi.nlm.nih.gov) and the UCSC Genome Browser (http://genome.ucsc.edu/).

Furthermore, the portal BioGPS (http://biogps.gnf.org/\#goto=welcome)

Was used to determine the expression levels of each gene per tissue.

Results: Significant differences were found for the non-coding elements of the chromatin in that associated genes, in comparison with controls (Kruskall-Wallis test, $\mathrm{P}=0.0341824$ ). The genes LEP, EBI3, PROCR, FSTL3, HEXB, INHBA and ENG were the ones with the highest $\mathrm{z}$ - score values in preeclampsic placenta.

Conclusion: The application of computational tools has become a powerful instrument for the integrated analysis of gene expression and its role in the pathogenesis of PE. This would lead to an early detection of affected women.

Keywords: Preeclampsia. Gene expression. Expression profiles. Meta-analysis. Data mining. Bioinformatics. Chromatin. 


\title{
CARACTERIZAÇÃO ESTRUTURAL E FUNCIONAL DE GENES ASSOCIADOS À PRÉ-ECLÂMPSIA EXPRESSARAM EM HUMANOS PLACENTA
}

\author{
Título curto: Genes Associados à Pré-eclâmpsia
}

\begin{abstract}
Resumo
Introdução: A pré-eclâmpsia ainda é a principal causa perinatal Morbi-mortalidade; devido ao avanço na aplicação das ciências "ómicas" o conhecimento sobre sua etiologia molecular tem aumentado nos últimos anos, Isto levou à identificação de genes candidatos, que estariam envolvidos na sua Patogênese.
\end{abstract}

Objetivo: Para identificar esses genes, Expresso em placenta que está associada à pré-eclâmpsia e comparar as suas características estruturais e funcionais.

Métodos: A partir de uma revisão da literatura, foram encontrados 16 genes, cuja expressão na placenta foi asociada à patología. Extração de dados Foi realizada incluindo as seguintes variáveis genómicas: Número de genes, tamanho genômico, exon contagem de codificação, CpG ilhas e repetir elementos em uma janela de 100Kbp. Para a análise bioinformática, Utilizamos diferentes recursos do NCBI (www.ncbi.nlm.nih.gov) e do UCSC Genome Browser (http://genome.ucsc.edu/).

Além disso, o portal BioGPS (http://biogps.gnf.org/\#goto=welcome) foi utilizado para determinar os níveis de expressão de cada gene por tecido.

Resultados: Se encontrou diferenças significativas para os elementos não codificantes da cromatina nos genes associados, Em comparação com os controlos (teste de Kruskall-Wallis, $\mathrm{P}=0,0341824)$. Os genes LEP, EBI3, PROCR, FSTL3, HEXB, INHBA e ENG foram os que apresentaram os maiores valores de z-score na placenta pré-eclâmpsica.

Conclusão: A aplicação de ferramentas computacionais tornou-se um poderoso instrumento para a análise integrada da expressão gênica e seu papel na patogênese da PE. Isso levaria a uma detecção precoce das mulheres afetadas.

Palavras-chave: Pré-eclampsia, Expressão do gene, Perfis de expressão, Meta-análise, Mineração de dados, Bioinformática, Cromatina. 


\section{Introducción}

La Preeclampsia (PE), una hipertensión inducida por el embarazo, es la complicación clínica más común durante la gestación humana, a la que se le atribuye más del $42 \%$ de fallecimientos maternos en Colombia (1). Los eventos clínicos de Preeclampsia se manifiestan como un síndrome materno, con hipertensión arterial mayor de $140 / 90 \mathrm{mmHg}$ y proteinuria (>0.3 g/24 h) con o sin la presencia de síndrome multiórgano; o como un síndrome fetal, con restricción del crecimiento fetal, oligohidroaminos; con diagnóstico imageneológico mediante Eco-Doppler de arterias umbilicales anormales y un crecimiento reducido de la placenta con infartos (2-6).

Existen varios factores que pueden predisponer a las embarazadas a desarrollar la enfermedad, sin embargo, a pesar de que tiene gran impacto en la salud humana (en términos de prevalencia y consecuencias), se desconoce mucho de su etiología, con la consecuente falta de métodos adecuados para su prevención y tratamiento $(7,8)$.

Algunos estudios se han enfocado a la placenta como fuente de la enfermedad, puesto que todos los signos y síntomas típicos de PE desaparecen al extraerla. Además, esta enfermedad puede ocurrir en embarazos molares donde este órgano está presente, mas no el feto (9) y el único tratamiento efectivo es extraerla (10). En la PE, la invasión trofoblástica es defectuosa y las arterias espirales mantienen su revestimiento endotelial y muscular comprometiendo el flujo sanguíneo en el espacio intervelloso; con ello se restringe el suministro sanguíneo a la placenta y al feto, lo cual promueve la hipoxia isquémica y un estrés oxidativo (11-15).
Los perfiles de expresión que se obtienen del uso de las micromatrices de ADN son una herramienta eficaz para estudiar la expresión de genes en aquellos desórdenes complejos, como la PE (16-18). El uso de estas metodologías permite un acercamiento objetivo para lograr un mejor entendimiento de su patogénesis (19). Los perfiles de expresión de génica en placenta son un medio para confirmar o refutar si los genes y rutas candidatas previamente descritos, están relacionados con la enfermedad (20). Así pues, un mejor entendimiento de los cambios de expresión de genes involucrados, podría convertirse en un biomarcador que permitiría la detección temprana de afectadas usando métodos no invasivos (21).

El presente estudio tuvo como objetivo identificar algunos genes expresados en placenta que están asociados con la preeclampsia, analizar sus perfiles de expresión, así como estudiar diferentes características de su cromatina asociada en una extensión de $100 \mathrm{Kpb}$ y compararla con la de genes no asociados, además de identificar si participan en procesos asociados a la etiología de la PE en la placenta.

\section{Materiales y métodos}

\section{Análisis Bioinformáticos}

Del 2010 al 2014 se buscaron, a partir de la base de datos PubMed del National Center for Biotechnology Information (NCBI), siguiendo los parámetros consignados en la Tabla 1, artículos que reportaran la expresión de genes tanto en placenta como en PE. Para este trabajo, se seleccionaron aquellos genes diferencialmente expresados, reportados en dos o más artículos. A cada uno de ellos se les calculó el valor de su expresión mediante el cálculo de su puntaje z y su cambio promedio.

Tabla 1. Número de artículos científicos encontrados en PubMed con cada filtro.

\begin{tabular}{|l|c|c|c|c|c|}
\hline Palabra clave & Preeclampsia & $\begin{array}{c}+ \\
\text { Perfiles de expresión }\end{array}$ & $\begin{array}{c}++ \\
\text { Micromatrices } \\
\text { de ADN }\end{array}$ & $\begin{array}{c}++ \\
\text { Placenta }\end{array}$ & valor P $\geq \mathbf{1 , 5}$ \\
\hline $\begin{array}{l}\text { Número de } \\
\text { resultados }\end{array}$ & 25.733 & 76 & 17 & 15 & 7 \\
\hline
\end{tabular}


Para realizar la búsqueda y análisis descritos a continuación, se utilizaron las bases de datos consignadas en la Tabla 2. Del Gene Entrez del NCBI, se obtuvo información sobre información bibliográfica, contexto genómico, interacciones y ontología de cada gen (Tabla 3). De la base de datos Nucleotide, se obtuvieron, en formato FASTA, las secuencias de los correspondientes ARNm. Así mismo las distintas secuencias nucleotidicas se alinearon, utilizando el programa BLAT del Genome Browser
UCSC, con el fin de recopilar información sobre tamaño de los genes, número de exones e información adicional sobre el modelo del gen. Adicionalmente, se hizo una exploración genómica, en una ventana de $100 \mathrm{Kpb}$, de las características de la cromatina de cada uno de los genes seleccionados usando el programa BLAST del NCBI. Los datos obtenidos sobre familias y clases de los distintos elementos repetidos (ER) fueron organizados en tablas dinámicas para su posterior análisis.

Tabla 2. Bases de datos empleadas para la minería de datos ejecutada en este trabajo.

\begin{tabular}{|l|l|}
\hline \multicolumn{1}{|c|}{ Bases de datos } & \multicolumn{1}{c|}{ Dirección electrónica } \\
\hline National Center for Biotechnology Information NCBI & www.ncbi.nlm.nih.gov \\
\hline PubMed & http://www.ncbi.nlm.nih.gov/pubmed/ \\
\hline Gene - Genes and mapped phenotypes & http://www.ncbi.nlm.nih.gov/gene/ \\
\hline BioGPS (Gene LinkOut) & http://biogps.gnf.org/\#goto=welcome \\
\hline Nucleotide - Alphabet of Life & http://www.ncbi.nlm.nih.gov/nucleotide/ \\
\hline Nucleotide BLAST & http://blast.ncbi.nlm.nih.gov \\
\hline UCSC Genome Bioinformatics & http://genome.ucsc.edu/ \\
\hline BLAT Search Genome & http://genome.ucsc.edu/cgi-bin/hgBlat \\
\hline
\end{tabular}

Mediante el método de números al azar, se seleccionaron 16 genes humanos como controles que estaban listados en la base de datos Gene del NCBI y que no se expresaban en placenta; a ellos se les realizó el mismo procedimiento.

Se efectuó un análisis bioinformático usando los diferentes recursos del NCBI y del Genome Browser de la UCSC, consignando la información obtenida en hojas de cálculo de Excel 2010 en tablas dinámicas y posteriormente en gráficas. Para corroborar que los genes seleccionados se expresaran en la placenta, se consultó, el "Gene LinkOut", además del portal BioGPS $(22,23)$. Los datos de expresión tejido específica obtenidos con estas plataformas, fueron estandarizados, obteniendo un puntaje $\mathrm{z}$ para cada gen; para ello se aplicó la siguiente fórmula:

Análisis estadísticos

Para cada una de las variables cuantitativas consignados en la Tabla 3, se empleó el software STATGRAPHICS
Centurion XVI Versión 16.1.02, se calcularon los valores promedio de cada una de ellas en una extensión de $100 \mathrm{Kpb}$ del genoma asociado. De otra parte, para cada familia de elementos repetidos, se sumó el número registrado en los $100 \mathrm{Kpb}$ que rodeaban cada uno de los genes; así se obtuvo el valor de la densidad, calculada como el número total de integrantes de cada familia para genes asociados y para genes control en la extensión de $100 \mathrm{Kpb}$.

Con los valores de puntaje $\mathrm{z}$ obtenidos para la expresión en placenta de los genes seleccionados, se calculó un Análisis de Conglomerados, tomando como medida el cuadrado de la media Euclidiana. Se aplicó la prueba Kruskal-Wallis y Friedman para calcular si había diferencias estadísticamente significativas en las medianas de las variables del estudio, tanto en la cromatina que contiene los elementos no codificantes de los genes asociados, como en los controles, al igual que para la cromatina codificante asociada a los genes.

$$
\text { Puntaje } \mathbf{z}=\frac{\text { [Intensidad de expresión del gen] }- \text { [Intensidad promedio en todos los genes] }}{\text { Desviación estándar de la Intensidad de todos los genes }}
$$


Tabla 3. Variables genómicas empleadas en el análisis bioinformático de la preeclampsia.

\begin{tabular}{|l|l|l|}
\hline \multicolumn{1}{|c|}{ Variable } & \multicolumn{1}{c|}{ Descripción } & Tipo \\
\hline Locus & Posición del gen en el cromosoma. & Cualitativa \\
\hline Número de genes en $100 \mathrm{Kpb}$ & $\begin{array}{l}\text { Número de genes que han sido anotados en los contigs } \\
\text { genómicos. Incluye genes conocidos y putativos, ubicados } \\
\text { como resultado de alineamientos de ARNm con los contigs. }\end{array}$ & Cuantitativa \\
\hline Tamaño del gen & Longitud del gen en pares de bases Kilopares de bases (Kpb). & Cuantitativa \\
\hline Número de exones codificantes & Número de exones codificantes & Cuantitativa \\
\hline Islas CpG & Regiones de alto contenido de G + C en la secuencia analizada. & Cuantitativa \\
\hline Elementos repetidos & Número de elementos repetitivos en la secuencia analizada. & Cuantitativa \\
\hline
\end{tabular}

\section{Resultados}

\section{Revisión de literatura}

De la revisión de 25,733 artículos consignados en el PubMed con el descriptor placenta, se encontraron siete que reportaban perfiles de expresión de genes a partir de datos consignados de experimentos de micromatrices de ADN en muestras de placenta de mujeres con preeclampsia (Tabla 1). De éstos, se seleccionaron 16 genes diferencialmente expresados, que tenían en común dos o más artículos y cumplian con los requisitos de establecidos en la búsqueda bibliográfica.

\section{Expresión génica diferencial}

La información general y de las categorías GO de cada uno de los 16 genes seleccionados aportada por la base de datos Reference Sequence (RefSeq) y PubMed para el NCBI, está organizada en la Tabla 4. Todos ellos codifican para proteínas y están ubicados en diferentes cromosomas, con excepción de dos parejas que están localizadas en un mismo cromosoma. Al organizar los valores puntaje z de cada uno de los genes estudiados y compararlos con el su cambio promedio (Figura 1), se determinó que los genes que codifican para LEP, EBI3, PROCR, FSTL3, HEXB, INHBA, ENG fueron los de mayor puntaje $z \mathrm{y}$ también se expresaron diferencialmente en mujeres con preeclampsia (Figura 2).

\section{Características de la cromatina asociada}

No se encontraron diferencias significativas en la cromatina codificante asociada a los genes expresados en preeclampsia con relación a los genes control (Prueba de Kruskall-Wallis, $\mathrm{P}=0$,0804127) (t Estadístico = 6,74699) (Figura 3A). Sin embargo, en la cromatina de las familias de elementos repetidos CR1, L1, ERV y RTE, se encontraron diferencias entre la asociada a preeclampsia y la de los controles (Prueba de Kruskall-Wallis, $\mathrm{P}=0.0341824)$ (Estadístico $=16.6316$ ) (Figura 3B).

\section{Discusión}

El tejido empleado en los estudios tomados como referencia para este trabajo fue la placa basal, que es donde ocurre inicialmente la invasión del citotrofoblasto; en este sentido, se ha descrito que esta área específica de la placenta es la más afectada por la preeclampsia (24). Además, cabe resaltar que la edad gestacional también es un factor de riesgo importante a tener en cuenta, pues estudios previos han revelado diferencias entre la mitad del periodo gestacional y su término $(25,26)$.

En este estudio, las placentas analizadas, correspondieron a mujeres en tercer trimestre, así pues, los datos referentes a los genes analizados que participan las rutas metabólicas implicadas en la patología, representarían el último punto de lo que presumiblemente es una cascada de eventos que se darían a lo largo de la gestación (27).

En su mayoría, los distintos estudios con relación a la preeclampsia, presentan resultados contradictorios que han dado lugar a múltiples explicaciones con relación a su la patofisiología, planteando la complejidad de 
Tabla 4. Información general sobre genes seleccionados asociados con PE.

\begin{tabular}{|c|c|c|c|}
\hline Símbolo & Nombre en inglés & Locus & Funciones \\
\hline BCL6 & B-cell CLL/lymphoma 6 & $3 q 27$ & $\begin{array}{l}\text { Involucrado en la regulación de respuesta inmune; en la } \\
\text { regulación negativa de apoptosis de las células B y del } \\
\text { crecimiento celular. }\end{array}$ \\
\hline CA10 & Carbonic anhydrase $\mathrm{X}$ & $17 q 21.33$ & $\begin{array}{l}\text { Cataliza la hidratación reversible del dióxido de carbono en } \\
\text { varios procesos fisiológicos. }\end{array}$ \\
\hline COL17A1 & $\begin{array}{l}\text { collagen, type XVII, alpha } \\
1\end{array}$ & $10 \mathrm{q} 24.3$ & $\begin{array}{l}\text { Componente estructural de hemidesmosomas, media la } \\
\text { adhesión de queratinocitos a la membrana subyacente. }\end{array}$ \\
\hline EBI3 & $\begin{array}{l}\text { Epstein-Barr virus induced } \\
3\end{array}$ & $19 \mathrm{p} 13.3$ & $\begin{array}{l}\text { Al formar interleucina } 27 \text { (IL-27) regula las células T y la } \\
\text { respuesta inflamatoria. }\end{array}$ \\
\hline ENG & Endoglin & 9q33-q34.1 & $\begin{array}{l}\text { Regulación negativa de la proliferación celular endotelial y la } \\
\text { modelación de vasos sanguíneos. }\end{array}$ \\
\hline FLT1 & $\begin{array}{l}\text { Fms-related tyrosine } \\
\text { kinase } 1 \text { (vascular } \\
\text { Endothelial growth factor/ } \\
\text { vascular permeability } \\
\text { factor receptor) }\end{array}$ & $13 q 12$ & $\begin{array}{l}\text { Interactúa con el factor de crecimiento endotelial vascular } \\
\text { y se une al factor de crecimiento de la placenta. Juega } \\
\text { un papel importante en angiogénesis y vasculogénesis. } \\
\text { Se expresa en células endoteliales vasculares y células del } \\
\text { trofoblasto }\end{array}$ \\
\hline FSTL3 & $\begin{array}{l}\text { Follistatin-like } 3 \text { (secreted } \\
\text { glycoprotein) }\end{array}$ & $19 \mathrm{p} 13$ & $\begin{array}{l}\text { Es una proteína de unión a activina que regula positivamente } \\
\text { la adhesión célula-célula y la transcripción. }\end{array}$ \\
\hline HEXB & $\begin{array}{l}\text { Hexosaminidase B (beta } \\
\text { polypeptide) }\end{array}$ & $5 q 13$ & $\begin{array}{l}\text { Involucrado en unión a azúcar, metabolismo de } \\
\text { carbohidratos, desarrollo celular y de los sistemas inmunes y } \\
\text { linfático. }\end{array}$ \\
\hline INHA & Inhibin, alpha & 2q33-q36 & $\begin{array}{l}\text { Regula negativamente la secreción de la hormona folículo } \\
\text { estimulante, regula la proliferación celular, apoptosis, } \\
\text { respuesta inmune y secreción hormonal }\end{array}$ \\
\hline INHBA & Inhibin, beta A & 7p15-p13 & $\begin{array}{l}\text { Inhibe la secreción de FSH en la pituitaria, regula } \\
\text { negativamente la proliferación celular, tiene actividad } \\
\text { supresora de tumores. Dado que su expresión en tejidos } \\
\text { gonadales y extragonadales puede variar de manera tejido- } \\
\text { específica, se ha propuesto que puede ser un factor de } \\
\text { crecimiento/diferenciación y una hormona. Tiene actividad } \\
\text { de citoquina. }\end{array}$ \\
\hline LEP & Leptin & 7q31.3 & $\begin{array}{l}\text { Involucrado en metabolismo de carbohidratos, desarrollo de } \\
\text { la placenta, respuesta inmune e inflamatoria, hematopoyesis, } \\
\text { angiogénesis y curación de heridas. }\end{array}$ \\
\hline P HYHIP & $\begin{array}{l}\text { Phytanoyl-CoA } \\
\text { 2-hydroxylase interacting } \\
\text { protein }\end{array}$ & $8 \mathrm{p} 21.3$ & Juega un papel en el desarrollo del sistema central \\
\hline PROCR & $\begin{array}{l}\text { Protein } \mathrm{C} \text { receptor, } \\
\text { endothelial }\end{array}$ & $20 \mathrm{q} 11.2$ & $\begin{array}{l}\text { Está involucrado en la respuesta inmune, crecimiento y } \\
\text { proliferación celular, respuesta inflamatoria y coagulación } \\
\text { sanguínea -promueve la activación de la proteína C-. }\end{array}$ \\
\hline SASH1 & $\begin{array}{l}\text { SAM and SH3 domain } \\
\text { containing } 1\end{array}$ & $6 \mathrm{q} 24.3$ & $\begin{array}{l}\text { Función de unión de proteínas y actividad supresora de } \\
\text { tumores. }\end{array}$ \\
\hline SLC6A8 & $\begin{array}{l}\text { Solute carrier family } \\
6 \text { (neurotransmitter } \\
\text { transporter, creatine), } \\
\text { member } 8\end{array}$ & Xq28 & $\begin{array}{l}\text { Transporta creatina dentro y fuera de la célula, está } \\
\text { involucrada en el metabolismo del nitrógeno celular, } \\
\text { contracción muscular y transporte de neurotransmisores. }\end{array}$ \\
\hline ST5 & $\begin{array}{l}\text { Suppression of } \\
\text { tumorigenicity } 5\end{array}$ & $22 \mathrm{p} 15$ & $\begin{array}{l}\text { Regula la cinasa MAPK1/ERK2, está relacionada con la } \\
\text { morfología y crecimiento celular, tiene función de unión a } \\
\text { proteína. }\end{array}$ \\
\hline
\end{tabular}




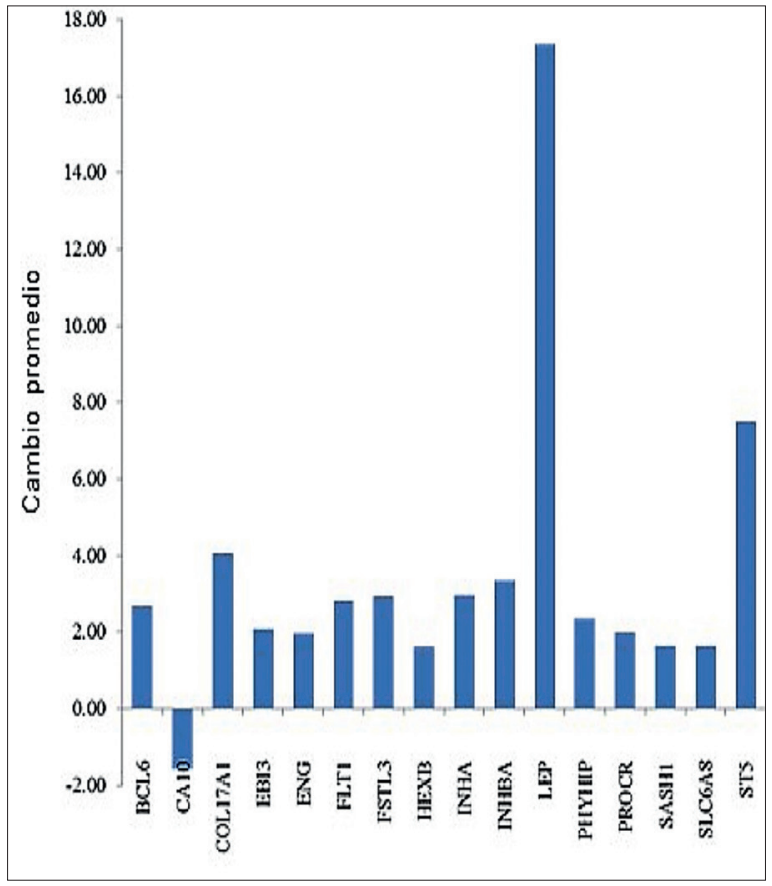

Figura 1. Distribución de los valores de cambio del promedio para los 16 genes asociados a la preeclampsia. CA10 fue el único que tuvo dentro de los analizados en este trabajo.

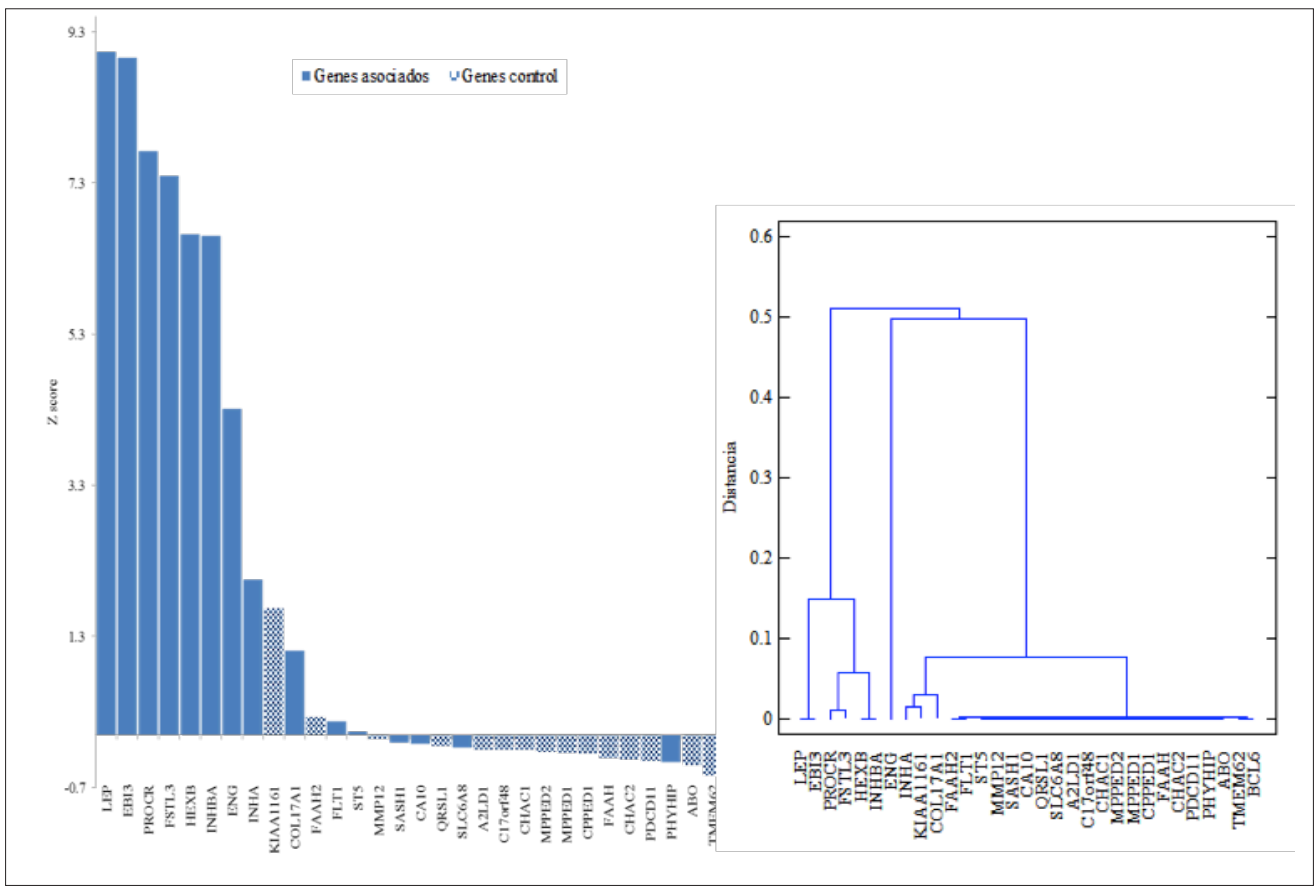

Figura 2. Expresión diferencial de genes en placenta de embarazadas preeclámpsicas. (A). Distribución de los valores de puntaje z de genes asociados y controles. (B). Dendrograma del Análisis de Conglomerados que muestra uno solo, con subgrupos en los que se destacan, por su elevada intensidad de expresión, los genes asociados LEP, EBI3, PROCR, FSTL3, HEXB, INHBA, ENG, INHA y COL17A1. 


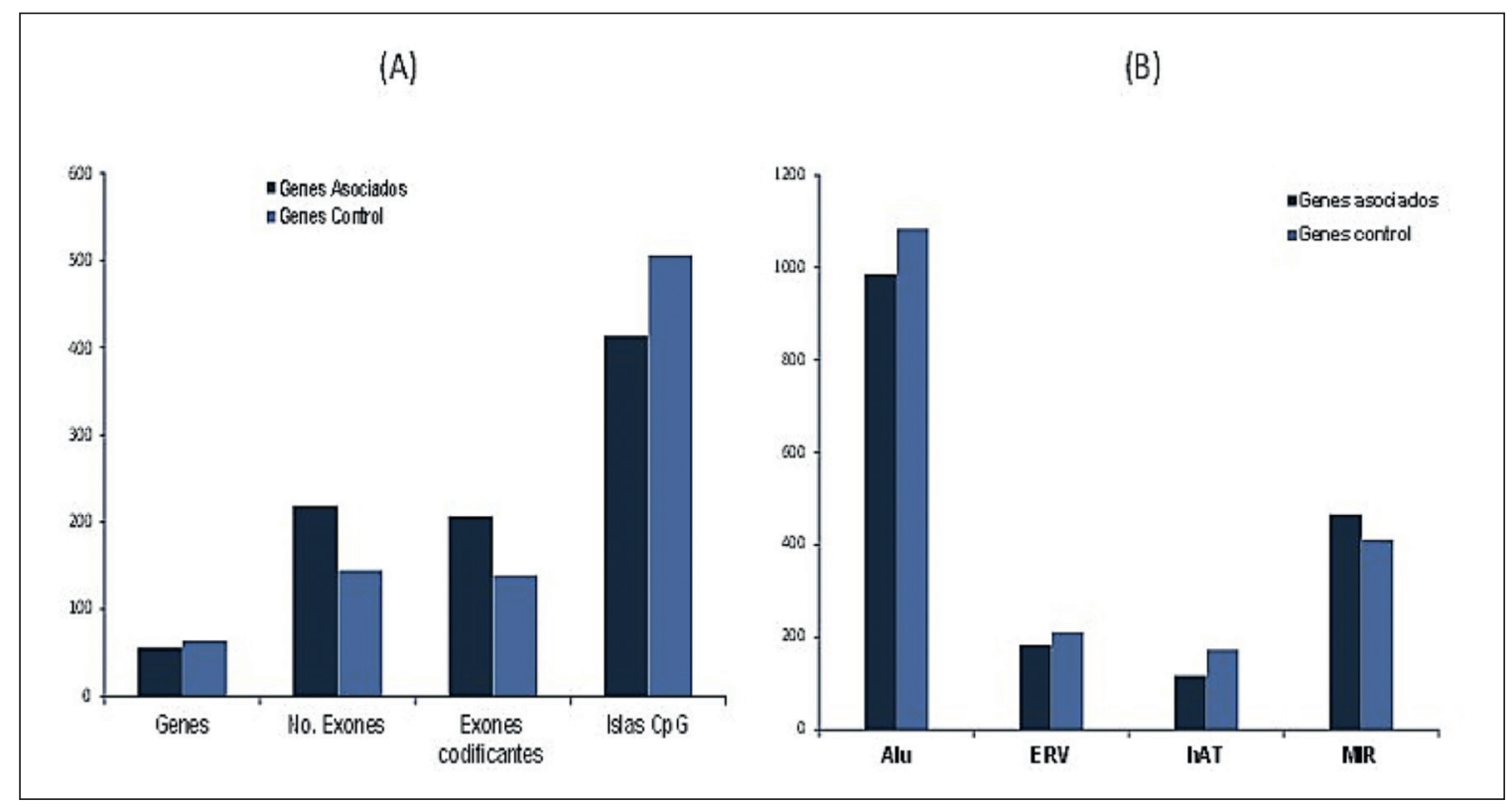

Figura 3. Comparación, entre los genes asociados y los controles, de las diferentes variables genómicas analizadas.

(A) Variables asociadas a la cromatina codificante.

(B) Variables asociadas a la cromatina que incluyó las familias de ER Alu, Erv, MIR y hAT.

la enfermedad (28). La aparición de esta enfermedad, por ejemplo, se ha asociado con múltiples mutaciones; sin embargo, se ha encontrado que gemelos monocigóticos pueden ser discordantes para la enfermedad, mostrando que el "maquillaje" genético de la persona puede contribuir con el desorden, aunque no lo explica completamente $(29,30)$. La respuesta podría estar entonces en la expresión diferencial de algunos genes involucrados en rutas metabólicas claves en la patogénesis de la PE o en factores que las alteran.

De acuerdo con los resultados obtenidos, la expresión diferencial de los genes podría relacionarse con la región no codificante de su cromatina asociada, particularmente con las familias de repeticiones CR1, L1, ERV y RTE. Se ha reportado previamente que las inserciones de elementos LINES (L1, CR1 y RTE) pueden alterar funciones genéticas, pues tienen secuencias funcionales que incluyen promotores, señales poliadenilación, donantes y aceptores de splicing del ARN, además de sitios de adhesión a la matriz nuclear (en humanos sólo L1 es activo) (31). Los efectos de la inserción de L1 en la composición del genoma y la expresión génica son numerosos, aparte de sus implicaciones en algunas enfermedades hereditarias y en tumorogénesis, también son responsables de la movilización de retrotransposones no autónomos, entre los que se incluyen los elementos Alu, y de la generación de pseudogenes (32); como un efecto general de los efectos de la movilización de transposones, es la generación de una inestabilidad genómica asociada a aquellas regiones de la cromatina que contiene genes cuya expresión es importante en el desarrollo de la PE.

Los resultados mostraron que los genes involucrados en la PE, la leptina (LEP) y la endoglina (ENG) tuvieron los mayores valores de puntaje $z$ en placentas preeclámpsicas. La función que desempeñan estos dos genes en la preeclampsia, permite proponer que la placenta estaría directamente expuesta al efecto incrementado de las lipoxinas séricas durante el embarazo. Estas participan en diferentes funciones in vitro dentro de las que se incluyen: La diferenciación trofoblástica (33), la producción de hormonas (34), la invasión trofoblástica (35) y el transporte de nutrientes (36).

En este sentido otros estudios bioquímicos también han puesto de manifiesto que, entre otros factores los niveles de adipoquinas, están significantemente más elevados en mujeres preeclámpsicas no obesas $(37,38)$.

Se ha demostrado que la transcripción de LEP durante el embarazo se da principalmente en el trofoblasto 
endocrinológicamente activo, y modula la función endocrina de la placenta al activar la liberación de citoquinas proinflamatorias (39-40). LEP induce la síntesis del factor de crecimiento endotelial vascular en células del citotrofoblasto cultivadas. Interrupciones en la señalización de las adipoquinas pueden inhibir la vía JAK/ STAT cuyo efecto sería importante en la patofisiología de la enfermedad (41). Por su parte, la ENG codifica para la endoglina, el cual es un co-receptor del factor transformante de crecimiento $\beta 1$ y $\beta 3$ sobre membranas de células del endotelio y sincitiotrofoblásticas. Esta es altamente incrementada en el suero materno de mujeres con PE y puede actuar en conjunto con sFLT1 e inducir a PE severa (42). Por otro lado, puede reducir la señalización endotelial del óxido nítrico al inhibir TGF $\beta-1$, causando la disfunción endotelial característica de esta enfermedad (42).

La respuesta inflamatoria incrementada y una mal adaptación inmune se asociaron con los genes BCL6, HEXB, INHBA, LEP, PROCR; estos pueden actuar de dos maneras en la aparición de la enfermedad. Primero, en conjunto con la predisposición genética, pues influirían en una placentación deficiente (43), y segundo, promoverían la disfunción endotelial asociada a la PE (44).

Se tiene que la respuesta inmune ha sido de gran importancia en el estudio de la PE, debido a que, durante la placentación, las células naturales killer (NK), linfocitos del sistema inmune innato, producen una parte importante de la respuesta inflamatoria decidual y facilitan la placentación al secretar citoquinas que promueven la infiltración de las arterias espirales por el trofoblasto invasor (45). Uno de los genes relacionados con esta respuesta es EBI3, Epstein-Barr virus Induced gene 3, este se expresa altamente en células placentarias, incluyendo sincitiotrofoblastos y trofoblastos extravellosos, además de ser regulado positivamente en la circulación de mujeres embarazadas (46).

Esta información junto con el descubrimiento de que el péptido EBI3 es presentado por HLA-G, ha sugerido que este gen es un modulador inmune crucial en la relación materno-fetal $(42,47)$. El gen FSTL3, que codifica para la glicoproteína secretada follistatin like-3, al igual que INHBA, también participa en la vía de señalización del factor transformante de crecimiento beta -TGF $\beta$, y ha sido ampliamente reportado como expresado en placentas preeclámpsicas $(48,49)$. Esta vía de señalización, a su vez, está involucrada en la regulación del de- sarrollo vascular y la angiogénesis, incluyendo el brote de angiogénesis (50).

A manera de perspectivas y conclusiones, el entendimiento de los eventos moleculares asociados a PE, puede proveer la base del diseño de nuevas estrategias de prevención y tratamiento para mejorar los resultados en términos reproductivos $(51,52)$. En este trabajo se mostró que la aplicación de las herramientas bioinformáticas se convierte en un instrumento potente para el análisis integrado de la expresión de genes y su papel en la patogénesis de la $\mathrm{PE}$; particularmente se señalan como posibles biomarcadores la LEP, ENG, INHBA, EBI3 y FSTL3 por su expresión diferencial, y se destacan las diferencias significativas obtenidas al comparar secuencias no codificantes de genes asociados y control.

\section{Conflicto de intereses}

Los autores declaran no tener ningún conflicto de intereses en lo relacionado con la información consignada en este artículo.

\section{Financiación}

Este trabajo fue financiado por un proyecto de la convocatoria interna de la Vicerrectoría de Investigaciones de la Universidad del Valle en el 2014.

\section{Referencias}

1. Herrera JA, Herrera-Miranda R, Herrera-Escobar JP, Nieto-Díaz A. Reducción de la mortalidad materna por preeclampsia en Colombia - un análisis de series de tiempo interrumpido. Colombia Médica. 2014; 45:25-31.

2. Sircar M, Thadhani R, Karumanchi SA. Pathogenesis of preeclampsia. Curr Opin Nephrol Hypertens. 2015; 24:131-138. http://dx.doi.org/10.1097/MNH.0000000000000105

3. Mol BW, Roberts CT, Thangaratinam S, Magee LA, de Groot CJ, Hofmeyr GJ. Pre-eclampsia. Lancet. 2015; pii: S0140-6736.

4. Cohen JM, Beddaoui M, Kramer MS, Platt RW, Basso O, Kahn SR. Maternal Antioxidant Levels in Pregnancy and Risk of Preeclampsia and Small for Gestational Age Birth: A Systematic Review and Meta-Analysis. PLoS One. 2015; 10(8):e0135192.http://dx.doi.org/10.1371/journal. pone.0135192

5. Dekker GA. Management of preeclampsia. Pregnancy Hypertens. 2014;4(3):246-247.http://dx.doi.org/10.1016/j. preghy.2014.04.021 
6. Said J, G. Dekker G. Pre-eclamsia and trombophilia. Best Practice \& Research Clinical Obstetrics \& Gynaecology 2003;17(3): 441-458.http://dx.doi.org/10.1016/S15216934(03)00008-7

7. Gillon TE, Pels A, von Dadelszen P, MacDonell K, Magee LA. Hypertensive disorders of pregnancy: a systematic review of international clinical practice guidelines. PLoS One. 2014;9(12):e113715.http://dx.doi.org/10.1371/journal. pone.0113715

8. Kajii T, Ohama K. Androgenetic origin of hydatidiform mole. Nature 1977; 268(5621): 633-634.http://dx.doi. org/10.1038/268633a0

9. Hansson SR, Chen Y, Brodszki J, Chen M, Hernandez-Andrade E, Inman JM, et. al. Gene expression profiling of human placentas from preeclamptic and normotensive pregnancies. Mol Hum Reproduction. 2006; 12: 169-179.http://dx.doi. org/10.1093/molehr/gal011

10. Lyall F. The human placental bed revisited. Placenta 2002; 23:555-562. http://dx.doi.org/10.1053/plac.2002.0850

11. Lyall F. Development of the utero-placental circulation: the role of carbon monoxide and nitric oxide in trophoblast invasion and spiral artery transformation. Microscopy Res Technique. 2003; 60(4): 402-411.http://dx.doi.org/10.1002/jemt.10278

12. Garoby-Salom S, Vayssiere C, Salvayre R, Parant O, Negre-Salvayre A. Oxidative stress and preeclampsia: A review. Gynecol Obstet Fertility. 2015; pii: S1297-9589.

13. Gram M, Dolberg Anderson U, Johansson ME, Edström-Hägerwall A, Larsson I, Jälmby M, Hansson SR, Åkerström B. The Human Endogenous Protection System against Cell-Free Hemoglobin and Heme Is Overwhelmed in Preeclampsia and Provides Potential Biomarkers and Clinical Indicators. PLoS One. 2015; http://dx.doi.org/10.1371/ journal.pone.0138111

14. Vanwijk MJ, Kublickiene K, Boer K, Vanbavel E. Vascular function in preeclampsia. Cardiovascular Research. 2000; 47(1): 38-48.http://dx.doi.org/10.1016/S0008-6363(00)00087-0

15. Nishizawa H, Pryor-Koishi K, Kato T, Kowa H, Kurahashi H, Udagawa Y. Microarray Analysis of Differentially Expressed Fetal Genes in Placental Tissue Derived from Early and Late Onset Severe Pre-eclampsia. Placenta. 2007; 28: 487-497. http://dx.doi.org/10.1016/j.placenta.2006.05.010

16. Cox B, Leavey K, Nosi U, Wong F, Kingdom J. Placental transcriptome in development and pathology: expression, function, and methods of analysis. Am J Obstet Gynecol. 2015; 213 (Suppl):S138-151.http://dx.doi.org/10.1016/j. ajog.2015.07.046

17. Sõber S, Reiman M, Kikas T, Rull K, Inno R, Vaas P, Teesalu P, Marti JM, Mattila P, Laan M. Extensive shift in placental transcriptome profile in preeclampsia and placental origin of adverse pregnancy outcomes. Sci Rep. 2015; 5: 13336. ttp://dx.doi.org/10.1038/srep13336
18. Winn VD, Gormley M, Paquet AC, Kjaer-Sorensen K, Kramer A, Rumer KK, et al. Severe Preeclampsia-Related Changes in Gene Expression at the Maternal-Fetal Interface Include Sialic Acid-Binding Immunoglobulin-Like Lectin-6 and Pappalysin-2. Endocrinology. 2009; 150(1):452-462.http://dx.doi. org/10.1210/en.2008-0990

19. Enquobahrie DA, Meller M, Rice K, Psaty BM, Siscovick DS, Williams MA. Differential placental gene expression in preeclampsia. Am J Obst Gynecol. 2008; 199:566.e1-566.e11. http://dx.doi.org/10.1016/j.ajog.2008.04.020

20. Rajakumar A, Chua T, Handley DE, Bunce KD, Burke B, Hubel CA, et al. Maternal gene expression profiling during pregnancy and preeclampsia in human peripheral blood mononuclear cells. Placenta 2011; 32: 70-78.http://dx.doi. org/10.1016/j.placenta.2010.10.004

21. Su AI, Wiltshire T, Batalov S, Lapp H, Ching KA, Block D, et. al. A gene atlas of the mouse and human protein-encoding transcriptomes. Proc Natl Acad Sci USA. 2004; 101(16):60626067.http://dx.doi.org/10.1073/pnas.0400782101

22. Wu C, Orozco C, Boyer J, Leglise M, Goodale J, Batalov S, et al. BioGPS: an extensible and customizable portal for querying ang organizing gene annotation resources. Genome Biology 2009; 10(11): R130.http://dx.doi.org/10.1186/gb-200910-11-r130

23. Winn VD, Haimov-Kochman R, Paquet AC, Yang YJ, Madhusudhan MS, Gormley M, et. al. Gene expression profiling of the human maternal-fetal interface reveals dramatic changes between midgestation and term. Endocrinology 2007; 148:1059-1079.http://dx.doi.org/10.1210/en.2006-0683

24. Laresgoiti-Servitje E, Gomez-Lopez N. The pathophysiology of preeclampsia involves altered levels of angiogenic factors promoted by hypoxia and autoantibody-mediated mechanisms. Biol Reprod. 2012; 87(2):36.http://dx.doi.org/10.1095/ biolreprod.112.099861

25. Jeha D, Usta I, Ghulmiyyah L, Nassar A. A review of the risks and consequences of adolescent pregnancy. J Neonatal Perinatal Med. 2015 Mar 12. [Epub ahead of print].http://dx.doi. org/10.3233/NPM-15814038

26. Martinussen MP, Bracken MB, Triche EW, Jacobsen GW, Risnes KR. Folic acid supplementation in early pregnancy and the risk of preeclampsia, small for gestational age offspring and preterm delivery. Eur J Obstet Gynecol Reprod Biol. 2015;195:94-99. http://dx.doi.org/10.1016/j. ejogrb.2015.09.022

27. Boeldt DS, Hankes AC, Alvarez RE, Khurshid N, Balistreri M, Grummer MA, Yi F, Bird IM. Pregnancy programming and preeclampsia: identifying a human endothelial model to study pregnancy-adapted endothelial function and endothelial adaptive failure in preeclamptic subjects. Adv Exp Med Biol. 2014; 814:27-47.http://dx.doi.org/10.1007/978-1-4939-1031-1_4 28. Murphy MS, Bytautiene E, Saade G, Smith GN. Alterations to 
the maternal circulating proteome after pre-eclampsia. Am J Obstet Gynecol. 2015 Oct 14. pii: S0002-9378(15)01271-5.

29. Monk D. Genomic imprinting in the human placenta. Am J Obstet Gynecol. 2015; 213(4 Suppl):S152-S162.http://dx. doi.org/10.1016/j.ajog.2015.06.032

30. Calicchio R, Doridot L, Miralles F, Méhats C, Vaiman D1. DNA methylation, an epigenetic mode of gene expression regulation in reproductive science. Curr Pharm Des. 2014; 20(11):17261750.http://dx.doi.org/10.2174/13816128113199990517

31. Ichiyanagi K, Okada N. Mobility Pathways for Vertebrate L1, L2, CR1, and RTE Clade Retrotransposons. Mol Biol Evol 2001; 25(6):1148-1157.http://dx.doi.org/10.1093/molbev/msn061

32. Khazina E, Weichenrieder O. Non-LTR retrotransposons encode noncanonical RRM domains in their first open reading frame. Proc Natl Acad Sci USA. 2009; 106:731-736.http:// dx.doi.org/10.1073/pnas.0809964106

33. Schulz LC, Widmaier EP, Qiu J, Roberts RM. Effect of leptin on mouse trophoblast giant cells. Biol Reprod 2009; 80: 415424.http://dx.doi.org/10.1095/biolreprod.108.073130

34. Cameo P, Bischof P, Calvo JC. Effect of leptin on progesterone, human chorionic gonadotropin, and interleukin-6 secretion by human term trophoblast cells in culture. Biol Reprod 2003; 68: 472-477.http://dx.doi.org/10.1095/biolreprod.102.006122

35. Schulz LC, Widmaier EP. The effect of leptin on mouse trophoblast cell invasion. Biol Reprod 2004; 71:1963-1967. http://dx.doi.org/10.1095/biolreprod.104.032722

36. Jansson N, Greenwood SL, Johansson BR, Powell TL, Jansson $\mathrm{T}$. Leptin stimulates the activity of the system $\mathrm{A}$ amino acid transporter in human placental villous fragments. J Clin Endocrinol Metab 2003; 88: 1205-1211.http://dx.doi. org/10.1210/jc.2002-021332

37. Turgut A, Ozler A, Goruk NY, Tunç SY, Sak ME, Evsen MS, Evliyaoglu $\mathrm{O}$, Gul T. Serum levels of the adipokines, free fatty acids, and oxidative stress markers in obese and non-obese preeclamptic patients. Clin Exp Obstet Gynecol. 2015; 42:473-479.

38. Henson MC, Castracane VD. Leptin in pregnancy: an update. Biology of Reproduction 2006; 74:218-229. http://dx.doi. org/10.1095/biolreprod.105.045120

39. Rahardjo B, Widjajanto E, Sujuti H, Keman K. Different levels of IL-1 $\alpha$, IL-6, TNF- $\alpha$, NF-kB and PPAR- $\gamma$ in monocyte cultures exposed by plasma preeclampsia and normotensive pregnancy. Pregnancy Hypertens. 2014; 4:187-193. http://dx.doi. org/10.1016/j.preghy.2014.03.001

40. Kaartokallio T, Cervera A, Kyllönen A, Laivuori K. Gene expression profiling of pre-eclamptic placentae by RNA sequencing.Adicionalmente. Sci Rep. 2015; 5:14107. http://dx.doi. org/10.1038/srep14107

41. Challier JC, Uzan S. The human placenta and its pathologies: focus on oxygen. Med Sci (Paris). 2003; 19(11):1111-1120. http://dx.doi.org/10.1051/medsci/200319111111
42. Louwen F, Muschol-Steinmetz C, Reinhard J, Reitter A, Yuan J. A lesson for cancer research: placental microarray gene analysis in Preeclampsia. Oncotarget. 2012; 3(8): 759-773. http://dx.doi.org/10.18632/oncotarget.595

43. Redman C. The six stages of pre-eclampsia. Pregnancy Hypertens. 2014; 4(3):246. http://dx.doi.org/10.1016/j. preghy.2014.04.020

44. Torrado J, Farro I, Zócalo Y, Farro F, Sosa C, Scasso S, Alonso J, Bia D. Preeclampsia Is Associated with Increased Central Aortic Pressure, Elastic Arteries Stiffness and Wave Reflections, and Resting and Recruitable Endothelial Dysfunction. Int J Hypertens. 2015; 2015:720683. http://dx.doi. org/10.1155/2015/720683

45. Reyna-Villasmil E, Brice-o-Pérez C, Torres-Cepeda D. Inmunología, inflamación y Preeclampsia. Revista de Obstetricia y Ginecología de Venezuela. 2009; 69(2): 97-110.

46. Devergne O, Coulomb-L'Herminé A, Capel F, Moussa M, Capron, F. Expression of the Epstein-Barr virus-induced gene 3 , an interleukin-12 p40-related molecule, throughout human pregnancy: involvement of syncytiotrophoblasts and extravillous trophoblasts. The American Journal of Pathology. 2001; 159(5): 1763-1776. http://dx.doi.org/10.1016/S00029440(10)63023-4

47. Van Der Hoorn ML, Keijser R, Ris-Stalpers C, Afink G, Claas FH, Van Der Post JA et al. Increased EBI3 expression in placentas of preeclamptic patients. Journal of Reproductive Immunology. 2010; 81: 1-61. http://dx.doi.org/10.1016/j. jri.2010.06.129

48. Guo J, Tian T, Lu D, Xia G, Wang H, Dong M. Alterations of maternal serum and placental follistatin-like 3 and myostatin in pre-eclampsia. Journal of Obstetrics and Gynecology Research. 2012; 38(7): 988-996. http://dx.doi.org/10.1111/ j.1447-0756.2011.01823.x

49. Kleinrouweler CE, Van Uitert M, Moerland PD, Ris-Stalpers C, Van der Post JAM, Afink GB. Differentially expressed genes in the Pre-eclamptic placenta: A systematic review and meta-analysis. PLoS ONE. 2013; 8(7): e68991. http://dx. doi.org/10.1371/journal.pone.0068991

50. Dijke PT, Arthur HM. Extracellular control of TGF_ signaling in vascular development and disease. Nature Reviews. 2007; 8: 857-869. http://dx.doi.org/10.1038/nrm2262

51. Lowe SA, Bowyer L, Lust K, McMahon LP, Morton M, North RA, Paech M, Said JM. SOMANZ guidelines for the management of hypertensive disorders of pregnancy 2014. Aust N Z J Obstet Gynaecol. 2015; 55(5):e1-e29. http://dx.doi. org/10.1111/ajo.12399

52. Enquobahrie DA, Meller M, Rice K, Psaty BM, Siscovick DS, Williams MA. Differential placental gene expression in preeclampsia. American J Obstetrics \& Gynecology 2008; 199:566.e1-566.e11. http://dx.doi.org/10.1016/j. ajog.2008.04.020 